\title{
Cutaneous Melanoma cM1c TNM Finding v8
}

National Cancer Institute

\section{Source}

National Cancer Institute. Cutaneous Melanoma CM1C TNM Finding v8. NCI Thesaurus. Code C136903.

Cutaneous melanoma with distant metastasis to non-CNS visceral sites with or without M1a or M1b sites of disease. LDH level not recorded or unspecified. (from AJCC 8th Ed.) 